\title{
A prática de ensino supervisionada em Portugal: vozes e posicionamentos do(as) estudantes-estagiários(as)
}

\author{
Carolina Gonçalves ${ }^{1}$ \\ ORCID: 0000-0002-3176-2601 \\ Catarina Tomás ${ }^{1}$ \\ ORCID: 0000-0002-9220-964X
}

\section{Resumo}

Neste artigo, propõe-se analisar as concepções de 115 estudantes que frequentam os mestrados de formação de educadores(as) de infância e professores(as) do $1^{\circ}$ e do $2^{\circ}$ ciclo do ensino básico, em Portugal continental, procurando perceber o que pensam e como se posicionam em relação à prática de ensino supervisionada (PES). Metodologicamente, o inquérito por questionário aplicado é a referência empírica central e os resultados permitem identificar seis dimensões relativamente à PES: i) os significados atribuídos; ii) os modelos pedagógicos ou curriculares privilegiados; iii) as áreas científicas e referenciais de suporte; iv) as reflexões escritas; v) os pontos fortes e pontos fracos; e vi) as propostas de alteração à PES no atual plano de estudos. Os resultados possibilitam desenhar um retrato que é simultaneamente marcado pela cristalização - no que diz respeito aos referenciais teóricos mobilizados pelos(as) estudantes nas suas reflexões sobre a PES, à coexistência de modelos pedagógicos ou curriculares híbridos, inexistentes ou desvalorizados e à permanência do duo psicologia e pedagogia, na sua versão clássica, sem que se mobilizem outra áreas de conhecimento - e pela descristalização - no que diz respeito ao reconhecimento do lugar central que a PES ocupa na sua formação profissional, pela mobilização da fundamentação teórica que a maioria dos(as) estudantes afirma convocar aquando da realização das reflexões escritas e a estarem conscientes acerca do que precisam para um desenvolvimento efetivo da profissionalidade docente.

\section{Palavras-chave}

Formação de educadores(as) e professores(as) do $1^{\circ}$ e do $2^{\circ}$ ciclo do ensino básico Estudantes do ensino superior - Concepções - Prática de ensino supervisionada.

1- Instituto Politécnico de Lisboa, Escola Superior de Educação de Lisboa e Centro Interdisciplinar de Ciências Sociais (CICS.NOVA), Faculdade de Ciências Sociais e Humanas (FCSH/NOVA), Lisboa, Portugal. Contatos: carolinag@eselx.ipl.pt; ctomas@eselx.ipl.pt. 


\section{The supervised professional practice in Portugal: voices and positions of trainee teachers}

\section{Abstract}

This paper is intended to characterize the Supervised Professional Practice (SPP) drawing from the voices of 115 students who attend the master's degree for the training of Early Childhood Education and $1^{\text {st }}$ and $2^{\text {nd }}$ Cycle of Basic Education teachers in Continental Portugal, with an attempt to understand what they think and their opinions in relation to Supervised Professional Practice (SPP). Methodologically, the survey applied is the central empirical reference and the results allow us to identify six dimensions concerning SPP: i) meanings; ii) pedagogical or curricular models prioritized; iii) the supporting scientific and reference areas; $i v)$ the importance of written reflections; $v$ ) strengths and weaknesses; and vi) the proposed amendments to the SPP in the curriculum. The results, analysed using SPSS and analytical interpretation, make it possible to draw a picture that is simultaneously marked by crystallization and it also regards the theoretical framework and fields of knowledge mobilized by the students in their written reflections, as well as the decrystallization, resulting from being aware of what they need for an effective development to achieve teaching professionalism.

\section{Keywords}

Teacher training for the Early Childhood Education and 1st and 2nd cycle of basic education - Higher education students - Conceptions - Supervised professional practice.

\section{Introdução}

A longa história da formação de educadores(as) e professores(as) em Portugal (NÓVOA, 1998; ROLDÃO, 2000, 2007; CARDONA, 2008; FORMOSINHO, 2009; ESTRELA, 2010; VILARINHO, 2012) é pautada por múltiplas mudanças que marcam períodos de transições paradigmáticas nesse processo. Um desses marcos prende-se com a reconfiguração das políticas educativas e a formação destes(as) profissionais, simultaneamente à escala global, nacional e local, decorrente do Processo de Bolonha.

Este estudo tem como objetivo geral identificar e analisar as concepções dos(as) estudantes de cursos de mestrado profissionalizante sobre a prática de ensino supervisionada (PES). Para tal, foi aplicado um inquérito por questionário a 115 estudantes que frequentam os cursos de mestrado de formação de educadores(as) e de professores(as) - Mestrado em Educação Pré-Escolar (MEPE); Mestrado em Educação Pré-Escolar e Ensino do $1^{\circ}$ Ciclo do Ensino Básico (PE1 $\left.{ }^{\circ} \mathrm{CEB}\right)$; Ensino do $1^{\circ}$ Ciclo do Ensino Básico e de Português e História e Geografia de Portugal no $2^{\circ}$ Ciclo do Ensino Básico (MPHGP) e Ensino do $1^{\circ}$ Ciclo do 
Ensino Básico e de Matemática e Ciências Naturais no 2 Ciclo do Ensino Básico (MMCN) - procurando perceber o que pensam e como se posicionam em relação à PES, a partir de seis dimensões de análise: i) os significados atribuídos; ii) os modelos pedagógicos ou curriculares privilegiados; iii) as áreas científicas e referenciais de suporte; iv) as reflexões escritas; v) os pontos fortes e pontos fracos; e vi) as propostas de alteração à PES no atual plano de estudos.

A opção pelo estudo apresentado justificou-se por duas razões principais: (i) a afonia dos(as) estudantes de cursos de mestrado profissionalizante em Portugal na reflexão e na produção científica sobre a PES; e (ii) o entendimento que estes têm da PES, como prática social, envolvendo o (re)conhecimento e a apropriação de referenciais teóricos e metodológicos que também necessitam de ser conhecidos por quem faz a formação.

Ao acionar a interdisciplinaridade e uma metodologia mista, usufruiremos de um retrato amplo e específico e de dados extensivos e intensivos sobre a PES a partir das concepções dos(as) estudantes. A realização deste estudo permitiu identificar duas orientações com sentido inverso, por um lado, deparamo-nos com a permanência do que a investigação tem problematizado em relação à PES, havendo questões que já há muito são identificadas como dificuldades da PES, marcadas por uma espécie de rigidez, e se mantêm até ao dia de hoje, que aqui denominamos de cristalização; e, por outro lado, abordagens e discursos, que decorrem de alterações políticas, práticas e até da própria investigação, que, contrariando um tempo histórico, buscam uma maior reflexividade e problematização ao lugar e função da PES na formação de educadores(as) e de professores(as), designado por nós como um processo de descristalização.

\section{A formação de educadores(as) de infância e professores(as) do ensino básico em Portugal}

A partir das orientações emanadas de diretivas europeias, caracterizando o que Ball (2001, p. 99) designa de “'convergência de políticas' ou transferência de políticas ou ainda empréstimo de políticas”, assiste-se a um conjunto de alterações no já longo e complexo processo de formação de educadores(as) e professores(as), via adesão ao Processo de Bolonha, em 1999. Lima, Azevedo e Catani (2008, p. 14) apresentam uma crítica a este processo, considerando que se consubstancia numa política educacional supranacional, tendo em vista "um movimento em direção à convergência" não só a nível institucional e organizacional - sistema de graus, créditos, mobilidade etc. -, mas também ideológico - referencial pedagógico centrado no estudante; e na definição de perfis e de competências profissionais etc. - que marcam também um processo de redefinição de funções, identidade e trajetórias dos(as) profissionais de educação.

Apesar de as alterações serem de um amplo espectro e intensidade, para este trabalho considerou-se pertinente apresentar uma breve contextualização dos principais marcos nacionais na formação, a partir do Processo de Bolonha. Os anos de 2007 e 2014 revelam-se, assim, dois marcos fundamentais no que diz respeito à formação de educadores(as) e professores(as) em Portugal de que a Figura 1, sucintamente, pretende dar conta. 
Figura 1 - Marcos legais na formação de educadores(as) de infância e professores(as) em Portugal, 1986-2014

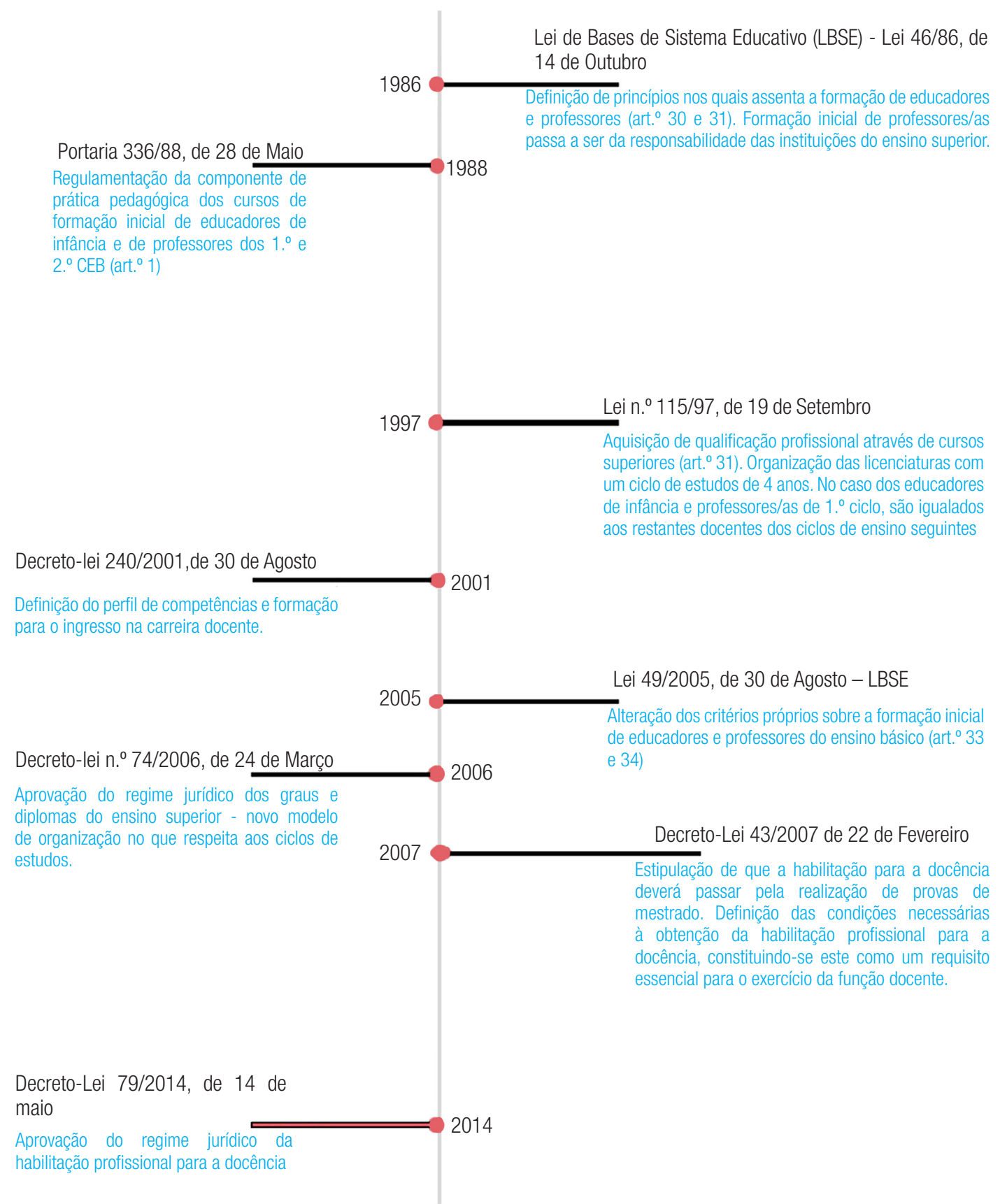

Fonte: elaboração própria. 
A análise das finalidades e dos objetivos presentes nos diplomas identificados, entre 1986 e 2014, possibilita destacar duas grandes tendências no processo de formação dos(as) profissionais que trabalham com crianças até aos 12 anos, sendo os dois diplomas legais, o Decreto-lei n. ${ }^{\circ}$ 43/2007, de 22 de Fevereiro, e o Decreto-Lei n. ${ }^{\circ}$ 79/2014, de 14 de maio, a sua face mais visivel. A primeira, de natureza estrutural, exige uma formação superior a estes(as) profissionais. A segunda, de natureza político-pedagógica, altera sucessivamente, em intensidade e densidade, a formação, e decorre de um processo de europeização, harmonização e convergência entre sistemas de ensino superior dos diversos países europeus, isto é, de compromissos e pressões internacionais assumidos com o Processo de Bolonha (SERRALHEIRO, 2005; FERREIRA; FERNANDES, 2015; TOMÁS; GONÇALVES, 2018; EUROPEAN COMMISSION/EACEA/EURYDICE, 2018) e de um processo de governação, ou seja, das opções políticas dos sucessivos governos relativamente à educação, em geral, e à formação de docentes, em particular. Podemos, por conseguinte, afirmar que se inaugura um novo paradigma, não isento de críticas (LIMA; AZEVEDO; CATANI, 2008; RAMALHO, 2015). Estas centram-se, tanto na escala internacional como nacional, em torno de um conjunto de questões: a crescente academização da formação; a pouca autonomia das instituições de ensino superior na organização dos planos de estudos; a ausência de participação dos(as) professores(as) e dos(as) estudantes do ensino superior na discussão desses planos; a sobrevalorização de determinadas áreas de conhecimento, como a matemática e o português, sobretudo entre 2011 e 2015; os discursos sobre a prática docente em permanente tensão, ou mesmo em contradição, com a ação pedagógica; o insuficiente número de horas PES na formação de educadores(as) e professores(as), tanto na licenciatura como no mestrado (ESTRELA; ESTEVES; RODRIGUES, 2002; LEITE, 2005; SERRALHEIRO, 2005; CARDONA, 2008; ALARCÃ0; ROLDÃ0, 2010; BIANCHETTI; SGUISSARDI, 2009; RAMALHO, 2015; COCHRAN-SMITH; VILLEGAS, 2016; FERREIRA, 2016; GALVÃO; PONTE, 2018). Parecendo ser evidente que estamos perante processos de cristalização de que os dados desta investigação também evidenciam, como veremos adiante.

\section{A prática de ensino supervisionada na formação de educadores(as) e professores(as)}

Atualmente, os cursos de formação de educadores(as) e professores(as) do $1^{\circ}$ e $2^{\circ}$ CEB organizam-se num ciclo bietápico constituído por uma licenciatura em educação básica (seis semestres), que não habilita para a docência, e um mestrado profissionalizante (dois a quatro semestres, consoante o nível ou níveis para os quais se está a formar²), que habilita para o exercício da profissão. No que diz respeito à PES, a legislação denomina iniciação à prática profissional, para referenciar a componente de formação da prática

\footnotetext{
2- "Entre as alterações introduzidas assinalam-se 0 aumento da duração dos mestrados em Educação Pré-Escolar e em Ensino do $1^{\circ}$ Ciclo do Ensino Básico de dois para três semestres, o aumento da duração do mestrado conjunto em Educação Pré-Escolar e Ensino do $1^{\circ}$ Ciclo do Ensino Básico de três para quatro semestres e a fixação em quatro semestres da duração dos restantes mestrados. Procede-se também ao desdobramento do mestrado em Ensino do $1^{\circ} \mathrm{e}$ do $2^{\circ}$ Ciclo do Ensino Básico separando a formação de docentes do $2^{\circ}$ ciclo de Português, História e Geografia de Portugal da formação de docentes do $2^{\circ}$ ciclo em Matemática e Ciências Naturais, desdobramento que está ajustado aos grupos de recrutamento e que permite reforçar a formação na área da docência" (Decreto-Lei nº 79/2014, p. 2820).
} 
pedagógica ( $1^{\circ}$ ciclo de estudos) e prática de ensino supervisionada para o estágio de natureza profissionalizante ( $2^{\circ}$ ciclo de estudos).

Dos vastos aspectos passíveis de serem investigados, centramos a nossa atenção na análise dos dois diplomas referidos anteriormente - o Decreto-lei n. ${ }^{\circ}$ 43/2007, de 22 de fevereiro e o Decreto-Lei n. ${ }^{\circ}$ 79/2014, de 14 de maio incidindo tal análise exclusivamente na PES (TOMÁS; GONÇALVES, 2018), na medida em que este também é o foco do trabalho de natureza empírica apresentado na seção seguinte.

Ao centrarmos a análise na transformação das finalidades e objetivos presentes nos dois documentos, destacam-se três grandes caraterísticas da PES no processo de reinstitucionalização da formação de educadores(as) e professores(as). A primeira, de natureza discursiva, aponta para uma valorização desta componente, ainda que mais explícita em 2007: "Valoriza-se ainda a área de iniciação à prática profissional consagrando-a, em grande parte, à prática de ensino supervisionada" (Decreto-lei n. ${ }^{\circ}$ 43/2007, p. 1321) e "a avaliação da unidade curricular referente à prática de ensino supervisionada assume um lugar especial na verificação da aptidão do futuro professor para satisfazer, de modo integrado, o conjunto das exigências que lhe são colocadas pelo desempenho docente no início do seu exercício" (Decreto-lei n. ${ }^{\circ}$ 43/2007, p. 1321). Manteve-se a mesma formulação nos dois diplomas relativamente à exigência da elaboração do relatório da PES e defesa pública (art. ${ }^{\circ} 17$ e art. $^{\circ} 20$, respectivamente). A segunda, de natureza organizacional, remete para a alteração da duração e os pesos das componentes de formação sobretudos as que estão associadas à área da docência e às didáticas específicas (art. ${ }^{\circ} 14$ do Decreto-Lei n 79 /2014). E, terceira, de natureza conceitual, remete para o estabelecimento nos dois decretos de um conjunto de regras (art. ${ }^{\circ} 14$ em 2007) e princípios (art. 11 em 2014) relativamente à PES. 0 detalhe é uma característica a salientar. Não obstante, há algumas alterações interessantes de referir do primeiro para o segundo decreto: a referência à educação de infância em 2014 (art. ${ }^{\circ} 11, \mathrm{n}^{\circ}$ 1, alínea a); e as atividades das PES passam de uma perspectiva centrada no desenvolvimento profissional para uma perspectiva centrada no sucesso acadêmico das crianças: “d) São concebidas numa perspectiva de desenvolvimento profissional dos formandos visando o desempenho como futuros docentes e promovendo uma postura crítica e reflexiva em relação aos desafios, processos e desempenhos do quotidiano profissional" passando a ser descrita como: "É concebida numa perspetiva de desenvolvimento profissional dos formandos e promove nestes uma atitude orientada para a permanente melhoria da aprendizagem dos seus alunos."

\section{Metodologia}

0 estudo assume uma abordagem mista (CRESWELL, 2014) e tem como objetivo identificar e analisar as concepções dos(as) estudantes sobre a PES, tal como referido anteriormente. Os(as) participantes no estudo frequentaram, em 2017/2018, um curso de mestrado de formação de educadores(as) de infância, de educadores(as) e professores(as) de $1^{\circ} \mathrm{CEB}$ ou de professores(as) de $1^{\circ}$ e de $2^{\circ} \mathrm{CEB}$. 
A partir de um processo multietápico: i) construiu-se um inquérito para a recolha dos dados aplicado aos(às) estudantes dos cursos acima referidos, entre março e abril de 2018, validado antes da sua aplicação; ii) identificaram-se os 66 cursos de mestrado profissionalizante de formação de educadores(as) e de professores(as) de $1^{\circ}$ e de $2^{\circ} \mathrm{CEB}$, em funcionamento no ano letivo de 2017/2018, a partir da página da Agência de Avaliação e Acreditação do Ensino Superior (A3ES) ${ }^{3}$; e iii) contactaram-se os(as) coordenadores(as) ou diretores(as) de curso a solicitar a divulgação do questionário junto dos(as) estudantes. Responderam ao inquérito por questionário 115 estudantes.

Para a análise estatística, foi utilizado o software IBM-SPSS Statistics versão 24 (Chicago, IL, EUA) e o nível de significância foi estabelecido $\mathrm{p}<0,05$. Foram realizadas estatísticas descritivas, incluindo média, desvio padrão, frequências e percentagens para a totalidade da amostra e por curso de mestrado. Para a análise descritiva, fez-se a categorização e codificação de todas as unidades de registo, com recurso ao software MAXQDA versão 18.0.8.

\section{Participantes}

Caracterizando os(as) 115 estudantes, destes(as), 111 (96,5\%) são mulheres e quatro são homens (3,5\%). Quanto aos escalões etários, 69 têm entre 21 e23 anos (60,0\%); 25 têm entre 24 e26 anos (21,7\%), nove têm entre 27 e29 anos (7,8\%), cinco têm entre 30 e 33 anos (4,3\%) e sete têm mais de 34 anos (6,1\%). No que diz respeito ao tempo de duração de cada PES já realizada, 20,9\% dos(as) estudantes indicaram entre um a dois meses; $55,7 \%$ indicaram três meses ou mais e 23,5\% não responderam à questão. É de referir que, quanto ao grau de satisfação, numa escala de 1 a 10 , em que 1 significa nada satisfeito(a) e 10 significa muito satisfeito(a), os(as) estudantes reportaram uma satisfação média de 7,17 pontos, revelando uma satisfação elevada com a PES.

Acrescenta-se, ainda, que a organização da PES varia em função das opções das instituições de ensino superior, ou seja, há quem tenha estado nos contextos de PES cinco dias seguidos, outros(as) três dias por semana, outros três manhãs por semana, entre outras modalidades. No caso dos mestrados que formam educadores(as) de infância, o lugar da PES em creche varia entre a sua exclusão, inclusão parcelar (menor número de horas em relação à PES em jardim de infância, por exemplo) ou inclusão total no plano de estudo.

Como se verifica no Tabela 1, a maior parte dos(as) estudantes frequenta instituições públicas, seja universidade ou instituto politécnico. Do curso do MEPE, 70,6\% frequentam a universidade pública e $84,2 \%$ estão no politécnico público. Cerca de $45 \%$ estão em instituições privadas, dos quais $29 \%$ na universidade e $15,8 \%$ no politécnico. 0 curso de $\mathrm{PE} 1{ }^{\circ} \mathrm{CEB}$ é frequentado por 54,5\% na universidade pública e $45,5 \%$ na privada; $93,3 \%$ dos estudantes que frequentam o politécnico estão numa instituição pública. Não se verifica frequência de estudantes dos cursos MPHGP e MMCN em universidade, seja pública ou privada. Dos(as) que estão no curso de MPHGP, todos frequentam o politécnico, 85,7\% do

3- A A3ES, criada em 2010, é responsável por analisar o cumprimento do que é legalmente definido para a formação de educadores(as) e professores(as) e avaliar a qualidade dos mesmos. 
dos estudantes estão numa instituição pública e 14,3\% numa instituição privada. Todos(as) os(as) estudantes do curso de MMCN frequentam o politécnico público.

Tabela 1 - Distribuição dos(as) estudantes/, no ano letivo 2017-2018, segundo o curso, a natureza jurídica e subsistema

\begin{tabular}{|c|c|c|c|c|c|}
\hline & & \multicolumn{4}{|c|}{ Subsistema } \\
\hline & & \multicolumn{2}{|c|}{ Universidade } & \multicolumn{2}{|c|}{ Politécnico } \\
\hline & & $n$ & $\%$ & $\mathrm{n}$ & $\%$ \\
\hline \multirow{3}{*}{ MEPE } & Pública & 12 & 70,6 & 32 & 84,2 \\
\hline & Privada & 5 & 29,4 & 6 & 15,8 \\
\hline & Total & 17 & 100,0 & 38 & 100,0 \\
\hline \multirow{3}{*}{ PE1. ${ }^{\circ} \mathrm{CEB}$} & Pública & 6 & 54,5 & 14 & 93,3 \\
\hline & Privada & 5 & 45,5 & 1 & 6,7 \\
\hline & Total & 11 & 100,0 & 15 & 100,0 \\
\hline \multirow{3}{*}{ MPHGP } & Pública & 0 & 0 & 12 & 85,7 \\
\hline & Privada & 0 & , 0 & 2 & 14,3 \\
\hline & Total & 0 & , 0 & 14 & 100,0 \\
\hline \multirow{3}{*}{ MMCN } & Pública & 0 & , 0 & 20 & 100,0 \\
\hline & Privada & 0 & , 0 & 0 &, 0 \\
\hline & Total & 0 & , 0 & 20 & 100,0 \\
\hline
\end{tabular}

Fonte: elaboração própria, com base nos dados recolhidos.

\section{Apresentação dos resultados e discussão}

Os resultados obtidos são apresentados e discutidos de acordo com as dimensões de análise definidas: i) os significados da PES; ii) os modelos pedagógicos ou curriculares privilegiados; iii) as áreas científıcas e referenciais de suporte; iv) as reflexões escritas; v) os pontos fortes e pontos fracos; vi) e as propostas de alteração à PES no plano de estudos atual.

(i) Aprendizagem, crescimento e/ou ação: os significados da PES

Os(as) estudantes remetem a PES para um lugar central na sua formação. Do total das respostas, 33,0\% consideram que é uma aprendizagem em contexto, destacando o papel dos(as) cooperantes e dos(as) professores(as) da instituição de ensino superior que os(as) acompanham: "vou aprender ao observar a prática de alguém com experiência" (Q7, MEPE); "uma aprendizagem significativa em contextos reais" (Q28, MPHGP); "muito a nível da aquisição de conhecimentos e contacto com a realidade” (Q84, PE1 $\left.{ }^{\circ} \mathrm{CEB}\right)$. Foram 30,4\% os(as) estudantes que colocaram a tônica no pressuposto da aplicabilidade, ou seja, que a PES é o lugar para pôr em prática a teoria, de que são exemplificativos os seguintes excertos: "Uma introdução ao contacto com a lecionação em $1^{\circ}$ ciclo nas áreas curriculares." (Q108, MPHGP); "Um primeiro contacto direto com a profissão, a consolidação da teoria através da prática” (Q115, PE1 $\left.{ }^{\circ} \mathrm{CEB}\right)$. Logo de seguida, 28,7\% consideraram que foi um processo de crescimento pessoal e/ou profissional: "Um crescimento pessoal e profissional, 
em que podemos deixar sobressair as nossas qualidades e aperfeiçoar os nossos erros e imperfeições” (Q83, MEPE). É de referir, ainda, que 7,8\% das respostas se encontram na categoria outras respostas, na sua maioria, críticas à forma como correu a PES.

Gráfico 1 - Significados da PES referidos pelos(as) estudantes

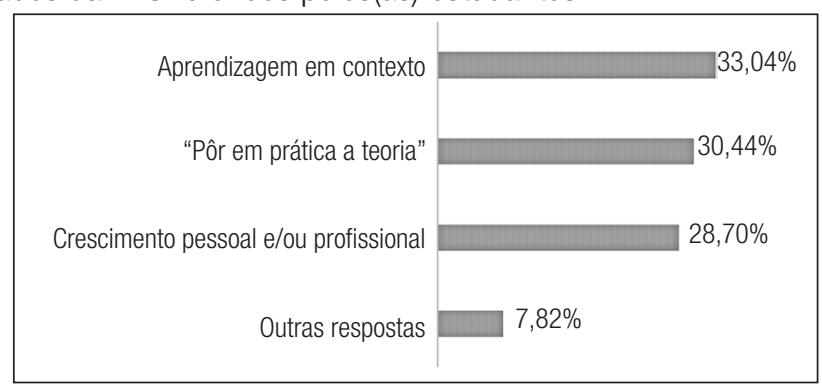

Fonte: elaboração própria, com base nos dados recolhidos.

Em sintese, os(as) estudantes remetem a PES para um lugar central na sua formação, o que concretiza o que diversos(as) autores defendem relativamente ao fato de a formação se construir dentro da profissão, destacando a centralidade da experiência (NÓVOA, 2009), na esteira do aprender fazendo, defendido por Dewey (2011 [1938]) e Freire (1996).

\section{(ii) Modelos pedagógicos ou curriculares privilegiados na PES}

Os(as) estudantes identificaram os modelos pedagógicos ou curriculares que privilegiam na PES $(\chi 2(24)=43,167, p=0,010)$, nomeadamente: o movimento da escola moderna $\left(\mathrm{MEM}^{4}\right)(27,0 \%)$; a pedagogia de projeto (10,4\%); "um pouco de cada" (9,6\%); o $H_{i g h S c o p e ~}$ (9,6\%); o MEM e HighScope (9,6\%); um modelo em função do contexto $(6,1 \%)$ e outros (16,5\%), que serão explicitados em seguida. Para além destes modelos identificados, 7,0\% dos(as) estudantes referem não recorrer a modelos e 4,3\% não souberam identificar um modelo ou não responderam à questão colocada.

Observa-se que são os(as) estudantes do MEPE que mais identificam modelos pedagógicos ou curriculares, em oposição aos(às) estudantes de MPHGP, que são o grupo que menos identifica modelos, seguindo-se dos(as) estudantes do curso de MMCN. Os(as) estudantes do MEPE são aqueles que mais referem a opção pelo MEM, pela combinação dos modelos MEM e HighScope ou apenas pelo HighScope. Com menor expressividade, os(as) estudantes do $\mathrm{PE} 1^{\circ} \mathrm{CEB}$ também fazem referência ao MEM e à pedagogia de projeto (Tabela 2).

Parecem ser os(as) estudantes de MMCN que mais referência fazem à utilização de outros modelos (sendo uma mistura de vários ou alguns mesmo inexistentes), também é neste curso que se verifica uma percentagem mais elevada de não resposta ou de não

4- Sobre o modelo, consultar: <http://www.movimentoescolamoderna.pt/>.

5- Sobre o modelo, consultar: <http://www.highscope-portugal.org/pt-pt/5-pontos-de-diferenca.asp>. 
sabe. A não referência ao uso de modelos é feita pelos(as) estudantes de todos os cursos, exceto de MPHGP.

A referência ao uso de um pouco de cada observa-se em todos os cursos, com predominância mais elevada no MEPE, o que terá de ser contextualizado pela própria história e práticas dos(as) educadores(as) de infância em Portugal (SILVA, 2017).

Tabela 2 - Comparação dos modelos pedagógicos ou curriculares privilegiados pelos estudantes na PES por curso de Mestrado (teste do Qui-Quadrado de independência)

\begin{tabular}{|c|c|c|c|c|c|c|}
\hline & \multirow{2}{*}{$\begin{array}{l}\text { Total } \\
\text { n (\%) }\end{array}$} & \multicolumn{4}{|c|}{ Curso } & \multirow[b]{2}{*}{$p$} \\
\hline & & MEPE & PE1. ${ }^{\circ} \mathrm{CEB}$ & MPHGP & MMCN & \\
\hline Modelos pedagógicos ou curriculares & & & & & & $0,010^{\mathrm{a}}$ \\
\hline MEM & $31(27,0)$ & $15(48,4)$ & $7(22,6)$ & $3(9,7)$ & $6(19,4)$ & \\
\hline Pedagogia de Projeto & $12(10,4)$ & $7(58,3)$ & $4(33,3)$ & $1(8,3)$ & $0(0,0)$ & \\
\hline "Um pouco de cada" & $11(9,6)$ & $5(45,5)$ & $3(27,3)$ & $2(9,1)$ & $1(9,1)$ & \\
\hline Highscope & $11(9,6)$ & $9(81,8)$ & $2(18,2)$ & $0(0,0)$ & $0(0,0)$ & \\
\hline MEM e Highscope & $11(9,6)$ & $10(90,9)$ & $1(9,1)$ & $0(0,0)$ & $0(0,0)$ & \\
\hline Modelo em função do contexto & $7(6,1)$ & $2(28,6)$ & $1(14,3)$ & $3(42,9)$ & $1(14,3)$ & \\
\hline Outros & $19(16,5)$ & $4(21,1)$ & $4(21,1)$ & $4(21,1)$ & $7(36,8)$ & \\
\hline Nenhum & $8(7,0)$ & $3(37,5)$ & $3(37,5)$ & $0(0,0)$ & $2(25,0)$ & \\
\hline NS / NR & $5(4,3)$ & $0(0,0)$ & $1(20,0)$ & $1(20,0)$ & $3(60,0)$ & \\
\hline
\end{tabular}

${ }^{a}$ Qui-quadrado

Fonte: elaboração própria, com base nos dados recolhidos.

0 modelo pedagógico do MEM foi eleito pelos(as) futuros(as) educadores(as) e/ou professores(as) como sendo um modelo privilegiado (27,0\%) "uma vez que é um modelo criado para o contexto de ensino em Portugal. E, consequentemente é um modelo amplo, no que diz respeito às práticas realizadas” (Q20, PE1 $\left.{ }^{\circ} \mathrm{CEB}\right)$. É também entendido como um dos modelos "que mais respeita a criança e que se enquadra mais na minha visão de criança” (Q3, PE1 $\left.{ }^{\circ} \mathrm{CEB}\right)$, permitindo "um ambiente fundado na democracia em sala e uma participação verdadeira e com significado social das crianças no seu processo de aprendizagem" (Q55, MPHGP). Há, contudo, referências ao modelo do MEM por este ter sido o único com o qual os(as) estudantes entraram em contato: "Apenas estagiei com o MEM e, do meu ponto de vista, apesar de ser muito benéfico para os alunos, é muito exaustivo para os professores e para os estagiários" (Q33, MMCN).

Outro dos modelos mais referidos pelos(as) estudantes é o modelo baseado na pedagogia de projeto $(10,4 \%)$, sobretudo porque é "extremamente importante [pois] o aluno [está] no centro das suas próprias aprendizagens e [é o] próprio construtor dos seus conhecimentos." (Q23, PE1 $\left.{ }^{\circ} \mathrm{CEB}\right)$.

Foi igualmente feita referência ao modelo pedagógico HighScope (9,6\%), identificando-se, neste caso, uma linha que permite identificar uma crença: "apesar de nunca ter estagiado num local com adotasse esse modelo pedagógico, os conhecimentos 
sobre este modelo que já pude adquirir na formação e através de leituras fazem-me acreditar que as intenções defendidas vão ao encontro do que eu defendo, nesta etapa da minha formação profissional” $\left(\mathrm{Q} 9, \mathrm{PE} 1^{\circ} \mathrm{CEB}\right)$; e uma outra mais pragmática que assenta no respeito pelo modelo já seguido no centro de estágio: "Modelo pedagógico Highscope porque a instituição onde estou o segue" (Q4 e Q5, PE1 $\left.{ }^{\circ} \mathrm{CEB}\right)$.

De seguida, o que se verifica são referências a combinações de pelo menos dois modelos pedagógicos. Por vezes, com proximidade ideológica, outras vezes com características dicotômicas.

A combinação do modelo pedagógico do MEM com o modelo HighScope (9,6\%) é justificada pelos(as) estudantes maioritariamente por uma questão de identificação com os dois modelos e de valorização do desenvolvimento da criança: "Identifico-me com o Movimento de Escola Moderna, mas também com o Highscope. Gosto da autonomia, liberdade de decisão que se dá às crianças, a organização da sala, da rotina e os materiais do MEM completam a ideia de democracia, e vêm a criança como um ser humano competente com ideias próprias" $\left(\mathrm{Q} 1, \mathrm{PE} 1^{\circ} \mathrm{CEB}\right)$.

Verifica-se ainda a opção por esta combinação por experiências prévias: o "Movimento de Escola Moderna e [o] modelo High Scope, visto já ter tido experiência nos dois modelos (...) e terem sido ambas muito valiosas" (Q6, PE1 $\left.{ }^{\circ} \mathrm{CEB}\right)$. Também com o mesmo valor percentual, referem uma combinação ainda mais híbrida, afırmando que privilegiam um pouco de cada $(9,6 \%)$ modelo pedagógico. As principais razões apontadas para esta opção relacionam-se essencialmente com o reconhecimento dos aspectos positivos ou das vantagens de cada modelo: "Um pouco de todos, não existe um modelo perfeito, pois cada grupo necessita de modelos e abordagens diferentes" (Q14, PE1 $\left.{ }^{\circ} \mathrm{CEB}\right)$; “Não sigo um modelo pedagógico específico, utilizo o que considero benéfico de vários modelos” (Q31, MMCN); "Não me identifico na totalidade com um modelo pedagógico em específico, sendo por isso que não me assumo como seguidora de um modelo único. Assim, a minha prática pedagógica traduz os princípios de diferentes modelos, sendo que tento ir 'beber' o que penso que de melhor tem cada modelo" (Q111, MEPE).

A adoção de um modelo pedagógico em função do contexto $(6,1 \%)$ é justificada pela adequação das práticas pedagógicas em articulação com o trabalho que já é desenvolvido nos centros de estágio: "Apesar de ter as minhas convicções, tento integrar-me nas práticas que encontro, dentro do possível. Para aprender e para melhor me integrar. A não ser que me depare com algo com que não concordo" (Q15, MMCN).

Na categoria outros (16,5\%), inserem-se os modelos e abordagens pedagógicas com menor frequência registada, tendo sido apenas mencionados por um máximo de três estudantes. Nesse sentido, na voz dos(as) estudantes, obtiveram-se referências aos seguintes modelos ou combinações de modelos: (i) tradicional e socioconstrutivista: "MEM com alguns traços do ensino tradicional. Porque acredito que não existe um modelo de ensino perfeito, mas que estes se podem complementar" (Q22, PE1 ${ }^{\circ} \mathrm{CEB}$ ); (ii) MEM e pedagogia de projeto: "são as mais trabalhadas ao longo da licenciatura e, portanto, aquelas com as quais sinto mais segurança para trabalhar" (Q42, MMCN); (iii) modelo socioconstrutivista: "Porque na minha opinião, estes levam a aprendizagens muito mais significativas para as crianças e fazem com que seja possível formar cidadãos ativos e conscientes o que, 
a meu ver, é o grande objetivo da educação" (Q94, MEPE); (iv) pedagogia participativa: "Privilegio o modelo de pedagogia participativa. Penso que este permite a realização de aprendizagens mais significativas por parte das crianças e é mais motivador para estas" (Q34, MMCN); (v) modelo dedutivo: "porque é o modelo ideal para que os alunos aprendam com a descoberta e participação" (Q82, MEPE).

Houve ainda estudantes que referiram não privilegiar nenhum (7\%) modelo pedagógico. Apesar da frequência em mestrado profissionalizante que habilita para a profıssão, 4,3\% dos(as) estudantes não identificam qual o modelo pedagógico a privilegiar ou não responderam à questão colocada.

Em suma, importa destacar não só os modelos privilegiados pelos(as) estudantes, que se adequam aos públicos com quem interagem na PES, mas também a elevada percentagem de referência a outros modelos, que nem sempre são identificados de forma correta, havendo mesmo, por vezes, referências a modelos pedagógicos inexistentes.

Para além dos modelos pedagógicos puros, os(as) estudantes parecem privilegiar o que designamos por modelos híbridos, ou seja, na ausência de seguirem uma única linha pedagógica, há uma comunhão entre, pelo menos, dois modelos. Cerca de 70\% das referências feitas apontam sobretudo para uma proliferação dos modelos híbridos, em que a sua conjugação até pode ser contraditória em termos de princípios pedagógicos, mas a qual nem parece colocar questões teóricas aos(às) estudantes, como é o caso, por exemplo, da conjugação do modelo tradicional com o modelo socioconstrutivista.

Importa ainda fazer referência ao fato de cerca de 10\% dos estudantes afirmarem que privilegiam um pouco de cada modelo pedagógico, despertando uma atenção com preocupação, no sentido em que pode fragilizar a organização do processo de desenvolvimento ou de aprendizagem no que diz respeito à concretização do desenvolvimento das crianças e/ou das suas aprendizagens.

Em sintese, destacam-se não só os modelos privilegiados pelos(as) estudantes, que se adequam aos públicos com quem interagem na PES, mas também a elevada percentagem de referência a outros modelos, que nem sempre são identificados de forma correta, havendo mesmo, por vezes, referências a modelos pedagógicos inexistentes.

\section{(iii) Áreas científicas e referenciais que suportam a PES}

A área científica educacional geral foi identificada por 63,5\% dos(as) estudantes como sendo aquela que mais suporta a PES, seguida do duo educacional geral e didáticas específicas $(10,4 \%)$. Estas últimas referem-se às áreas do mestrado que frequentam. Quando analisamos com maior atenção as suas subáreas, destacam-se o par psicologia e pedagogia (48,7\%), a pedagogia $(26,3 \%)$ e a psicologia $(14,5 \%)$. Com valores pouco relevantes, o trio psicologiapedagogia-sociologia $(6,6 \%)$, o par pedagogia-sociologia $(1,3 \%)$ e sociologia $(1,3 \%)$.

Em relação à reflexividade e à teorização da prática pedagógica, tão necessária quão difícil de se fazer, da opinião dos(as) estudantes, quando questionados acerca dos autores(as) que mais convocaram para a PES, sobretudo nas reflexões teóricas, parece sobressair duas premissas: (i) a valorização de autores clássicos da psicologia, como Lev Vygotsky e Jean Piaget; (ii) a existência de alguma especificidade em relação ao 
curso: nos mestrados que formam educadores(as) de infância - MEPE e PE $1^{\circ} \mathrm{CEB}$ - as principais referências indicadas foram: Gabriela Portugal, Assunção Folque, Júlia OliveiraFormosinho, Teresa Vasconcelos, Jacalyn Post e Mary Hohman, David Weikart e Mary Hohmann e as Orientações Curriculares para a Educação Pré-escolar ${ }^{6}$ (2016); nos MPHGP e MMCN, os autores mais referidos foram: Inês Sim-Sim, Maria do Céu Roldão, Sérgio Niza, Carlos Neto, Paulo Freire e Ministério da Educação. É ainda de assinalar que 18,26\% dos(as) estudantes não responderam à questão.

Gráfico 2 - Áreas científicas que suportam a PES identificadas pelos(as) estudantes

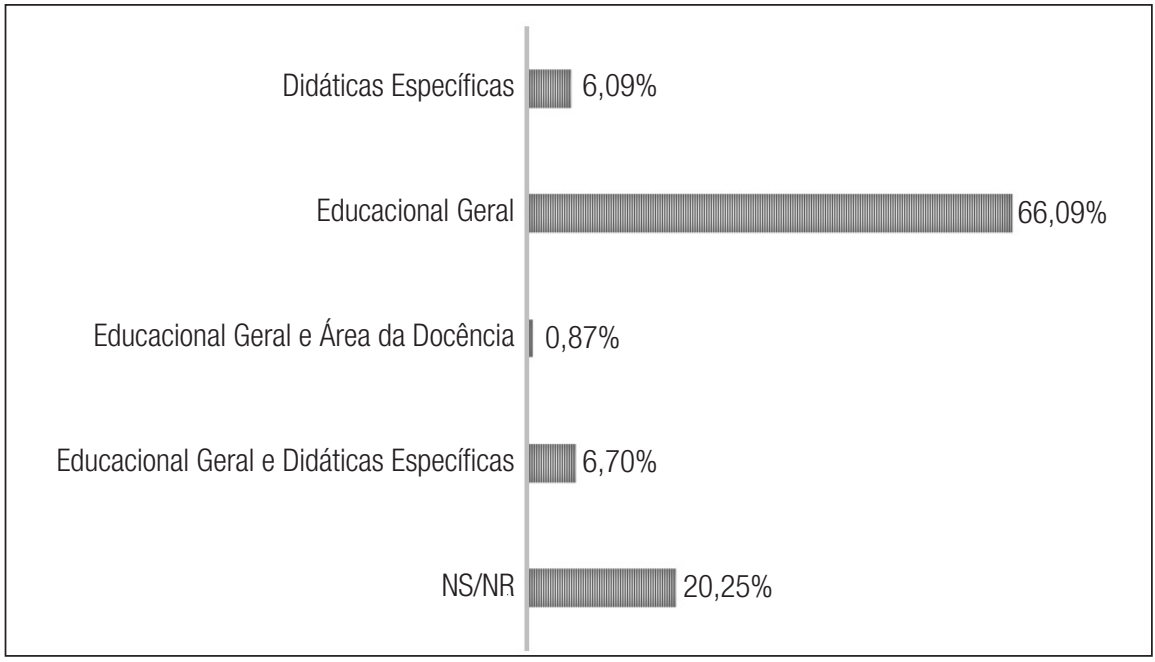

Fonte: elaboração própria, com base nos dados recolhidos.

Em síntese, estamos perante a coabitação dos grandes clássicos da psicologia, reconhecidos internacionalmente, e a especificidade da profissão que os(as) estudantes parecem só conseguir encontrá-la com maior expressão em autores(as) nacionais.

\section{(iv) As reflexões escritas durante a PES}

A maioria dos(as) estudantes (74,8\%) afirma que convoca fundamentação teórica aquando da realização das reflexões escritas, 12,2\% afırmam não o fazer e 13,0\% não responderam à questão. Daqueles que o fazem, 89,6\% consideram que as reflexões têm impacto na prática pedagógica: "Bastante acentuada, o que contribui para uma PES mais reflexiva e com sentido" (Q4, PE1 $\left.{ }^{\circ} \mathrm{CEB}\right)$. Apenas 10,4\% afirmam o contrário, de que o seguinte excerto é exemplificativo desse posicionamento: "A teoria é muito linda, mas depois nem sempre dá para aplicar na prática” $\left(\mathrm{Q} 8, \mathrm{PE} 1^{\circ} \mathrm{CEB}\right)$.

No que diz respeito à periocidade das reflexões $(\chi 2(8)=8,085, p=0,425), 41,7 \%$ afirmam realizá-las semanalmente, 20,9\% fazem diária e semanalmente; 14,8\% fá-lo quinzenal/

6- Ver: <http://www.dge.mec.pt/ocepe/sites/default/files/Orientacoes_Curriculares.pdf>. 
mensalmente e 7,0\% indicaram diariamente. Dentro desta periodicidade, verifica-se que, de um modo geral, quem faz reflexões no âmbito da PES recorre à fundamentação teórica. No entanto, aqueles(as) que as realizam semanalmente são quem mais recorre à fundamentação teórica (29,6\%), em oposição a quem realiza reflexões numa base diária (5,2\%). São também os(as) estudantes que realizam reflexões semanalmente quem não recorre à fundamentação teórica $(7,8 \%)$ ou que não responderam a esta questão $(4,3 \%)$.

Verifica-se uma correlação forte e positiva entre a periodicidade da realização de reflexões e a mobilização ou não de fundamentação teórica $(r=0,888)$, ou seja, variam no mesmo sentido e, quando uma aumenta, a outra também aumenta.

Tabela 3 - Periodicidade das reflexões sobre a PES

\begin{tabular}{|c|c|c|c|c|c|}
\hline & \multirow{2}{*}{$\begin{array}{l}\text { Total } \\
\mathrm{n}(\%)\end{array}$} & \multicolumn{3}{|c|}{$\begin{array}{c}\text { Faz ou não faz } \\
\text { fundamentação teórica }\end{array}$} & \multirow[b]{2}{*}{$\mathrm{p}$} \\
\hline & & Sim & Não & NS/NR & \\
\hline Periodicidade das reflexões sobre a PES & & & & & $N S^{a}$ \\
\hline Diárias & $8(7,0)$ & $6(5,2)$ & $1(0,9)$ & $1(0,9)$ & \\
\hline Semanais & $48(41,7)$ & $34(29,6)$ & $9(7,8)$ & $5(4,3)$ & \\
\hline Diárias e semanais & $24(20,9)$ & $21(18,3)$ & $1(0,9)$ & $2(1,7)$ & \\
\hline Quinzenais/Mensais & $17(14,8)$ & $13(11,3)$ & $2(1,7)$ & $2(1,7)$ & \\
\hline NS / NR & $18(15,7)$ & $12(10,4)$ & $1(0,9)$ & $5(4,3)$ & \\
\hline
\end{tabular}

aNS - Não Significativo

Fonte: elaboração própria, com base nos dados recolhidos.

A maioria dos(as) estudantes (71,8\%) afirma que as reflexões se configuram como um mecanismo de regulação/avaliação da ação - "Avaliar a minha própria prática; Avaliar as aprendizagens das crianças; melhorar metodologias que uso; Ajudam-me a evoluir enquanto profissional" (Q3, PE1 $\left.{ }^{\circ} \mathrm{CEB}\right)$ e "Considero que as reflexões, apoiadas em fundamentação teórica, são importantes na medida em que permitem à estudante pensar sobre a sua ação, refletir e reajustá-la ao grupo e a cada criança” (Q67, MEPE). Para 23,3\%, as reflexões assumem-se como um processo de introspecção: "Reflicto sobre a minha ação e tento melhorá-la" (Q27, MMCN) e "Considero que é um momento muito importante, pois enquanto realizamos as reflexões pensamos sobre o que ocorreu na prática, o que nos permite melhorar ou repensar a nossa prática” (Q48, MPHGP).

Quanto à avaliação da relação entre as reflexões e a ação pedagógica na PES, numa escala de 1 a 10 , em que 1 significa nada importante e 10 significa muito importante, os(as) estudantes reportaram uma satisfação média de 8,31 pontos, atribuindo uma importância elevada.

Em síntese, há um reconhecimento da importância da mobilização teórica no momento das reflexões escritas, parecendo possível inferir-se que há uma consciência de que os marcos teóricos ajudam na construção da profissão e no desenvolvimento profissional do(a) futuro(a) educador(a) ou professor(a). 


\section{(v) Pontos fortes e pontos fracos do atual modelo da PES}

Quando solicitados(as) a identificar três pontos fortes e três pontos fracos do atual modelo da PES, os(as) estudantes apresentaram fatores diversos, mas aqueles que são em comum relacionam-se essencialmente com a aprendizagem e desenvolvimento profissional; processo de supervisão e organização e duração da PES. Sempre que possível, utilizou-se a mesma categorização para os aspectos positivos e para os aspectos negativos. Sempre que os aspectos apontados pelos estudantes tiveram menos de dez unidades de registo, optou-se por registrá-los na subcategoria outros.

Para a dimensão dos pontos positivos (Tabela 4), destacam-se: a aprendizagem e desenvolvimento profissional (24,9\%); o processo de supervisão $(19,8 \%)$; a organização e duração da PES (14,7\%); os contextos de estágio (13,6\%); o processo reflexivo (10,7\%); a relação entre a teoria e a prática $(8,5 \%)$ e outros $(7,9 \%)$, nos quais se considera o processo de avaliação, o processo investigativo e o contato com os modelos pedagógicos.

Tabela 4 - Distribuição dos pontos fortes e dos pontos fracos identificados pelos(as) estudantes no atual modelo da PES

\begin{tabular}{|c|c|c|c|c|}
\hline & \multicolumn{2}{|c|}{ Ponto fortes da PES } & \multicolumn{2}{|c|}{ Pontos fracos da PES } \\
\hline & $\mathrm{n}$ & $\%$ & $n$ & $\%$ \\
\hline Aprendizagem e desenvolvimento profissional & 44 & 24,9 & - & - \\
\hline Processo/elementos de avaliação & - & - & 44 & 22,9 \\
\hline Processo supervisivo & 35 & 19,8 & 44 & 22,9 \\
\hline Organização e duração da PES & 26 & 14,7 & 47 & 24,5 \\
\hline Sobreposição da PES com UC teóricas & - & - & 18 & 9,4 \\
\hline Contextos de estágio & 24 & 13,6 & 13 & 6,8 \\
\hline Processo reflexivo & 19 & 10,7 & - & - \\
\hline Relação entre a teoria e a prática & 15 & 8,5 & - & - \\
\hline Outros & 14 & 7,9 & 16 & 8,3 \\
\hline Preparação científico-pedagógica & - & - & 10 & 5,2 \\
\hline
\end{tabular}

Fonte: elaboração própria, com base nos dados recolhidos.

A aprendizagem e desenvolvimento profissional (24,9\%) proporcionados pela PES encabeçam os pontos fortes identificados: "a aprendizagem que é feita no campo. A oportunidade de ter 3 semanas para observar e ambientar no grupo/turma” (Q14, PE1 $\left.{ }^{\circ} \mathrm{CEB}\right)$; "aprendizagem contínua; oportunidade de participar num novo contexto; crescimento enquanto futuros profissionais” (Q37, MEPE).

0 processo de supervisão $(19,8 \%)$ ganha visibilidade em opiniões que se relacionam com o fato de "ter uma supervisora disponível a responder às minhas questões" (Q13, MEPE); “acompanhamento dos professores orientadores/supervisores" (Q20, MPHGP); "o apoio dado pelos professores tutores e a sua compreensão para com os alunos em intervenção" (Q24, MPHGP); "Uso de críticas construtivas nas observações realizadas 
pelas professoras" (Q45, MMCN); “a periodicidade das visitas da orientadora da escola ajudam a estruturar a prática e a ultrapassar eventuais dificuldades” (Q54, MEPE).

A organização e duração da PES (14,7\%) são reconhecidas como o "tempo adequado para a pessoa se adaptar e conseguir resultados perante o grupo" (Q1, MEPE); e como um "bom período de prática, [com] possibilidade de intervir mais tempo" (Q11, MEPE). Assim como "o facto dos estágios no $2^{\circ}$ do mestrado serem realizados todos no segundo semestre, não se misturando com outras UC" (Q28, MPHGP), com "disponibilidade e calendarização do estágio fora do tempo das aulas/semestre" (Q30, MMCN) e "tempo extenso que dá espaço às estagiárias para que se apropriem do grupo e das suas características” (Q89, MEPE).

Os contextos de estágio (13,6\%) são destacados por serem selecionados através de "[uma] escolha prévia das instituições pela universidade" (Q3, MEPE) com "locais de estágio muito bons” (Q1, MEPE; Q41, MMCN).

0 processo reflexivo $(10,7 \%)$ implica "[uma] constante reflexão que fazemos." (Q2, MEPE), sendo igualmente "privilegiada a capacidade de reflexão, que consider[am] essencial num professor (Q24, MPHGP) e o "uso da reflexão para possíveis melhoramentos" (Q45, MMCN).

A relação entre a teoria e a prática $(8,5 \%)$ é valorizada pelo "facto de poder[em] colocar em prática o conhecimento teórico que adquir[em]" (Q2, MEPE; Q68, MEPE); "pode[m] pôr em prática alguns planos realizados durante os anos de estudo" (Q10, MEPE); e "viabiliza [ainda] a articulação entre a teoria e a prática em contextos reais" (Q49, MEPE).

Em outros (7,9\%), as opiniões centram-se essencialmente no processo avaliativo: “o portefólio contribui para uma reflexão crítica sobre a prática, fundamentando-se teoricamente o trabalho" (Q54, MEPE); "Multiplicidade de instrumentos de avaliação" (Q108, MPHGP); "a metodologia de avaliação que atribui igual peso à prática e à escrita do relatório e sua defesa” (Q111, MEPE). Para além disso, "permite [ainda] o contacto com modelos pedagógicos diferentes” (Q22, MMCN) e "favorece a investigação” (Q105, MEPE).

No que diz respeito à dimensão pontos fracos (Tabela 4), identificam-se as seguintes categorias: organização e duração da PES (24,5\%); processo/elementos de avaliação (22,9\%); processo de supervisão (22,9\%); sobreposição da PES com UC teóricas $(9,4 \%)$; contextos de estágio (6,8\%); preparação científico-pedagógica $(5,2 \%)$ e outros $(8,3 \%)$, nos quais se identifica o processo investigativo; a ausência de apoio financeiro; desarticulação entre a teoria e a prática; os modelos pedagógicos e o processo reflexivo.

A organização e duração da PES encabeça a categoria mais referida nesta dimensão, com incidência no "volume de trabalho pedido (aulas com trabalhos de grupo extensos e trabalhos individuais e tudo o que envolve o estágio - aprofundar um tema por semana desde o início do estágio, para além de ter de conhecer e me adaptar ao contexto em que estou)" (Q22, MMCN); “A organização dos calendários” (Q6, MMCN); "Duração curta do estágio no geral” (Q45, MMCN); “os horários de estágio são muito longos, e em consequência o tempo para reflexão, planeamento, avaliação que é tão importante como a própria ação é muito reduzido" (Q49, MEPE).

Relativamente à categoria processo/elementos de avaliação, a maioria dos(as) estudantes refere o excesso de trabalhos ou mesmo a falta de articulação entre os(as) 
diferentes supervisores(as) da PES. No entanto, há estudantes que consideram que os elementos de avaliação são insuficientes e afırmam que deve "haver mais elementos de avaliação" (Q66, MEPE).

0 processo de supervisão, também referido anteriormente como um ponto forte, encontra aqui expressão na dimensão dos pontos fracos, devido ao fato de "não haver uma orientação, antes da ação, que seja específica sobre o que será pedido durante o período de estágio" (Q13, PE1 $\left.{ }^{\circ} \mathrm{CEB}\right)$. Para além disso, as "poucas visitas e falta de bases para o orientador dar uma nota” $\left(\mathrm{Q} 1, \mathrm{PE} 1^{\circ} \mathrm{CEB}\right)$ também figuram entre as preocupações manifestadas pelos(as) estudantes.

A sobreposição da PES com UC teóricas $(9,4 \%)$ é também uma preocupação manifestada pelos(as) estudantes em diversas dimensões, pois as "Muitas disciplinas teóricas ao mesmo tempo do estágio (Q1, MEPE), no sentido em que "a existência de aulas em simultâneo com a prática [nem sempre têm uma] relação direta com a PES” (Q71, MEPE).

Os contextos de estágio (6,8\%) são enunciados devido à "falta de controlo nos locais de estágio, pois nem sempre as práticas que são realizadas nos mesmos são as melhores para que exista uma aprendizagem" $\left(\mathrm{Q} 14, \mathrm{PE} 1^{\circ} \mathrm{CEB}\right)$ ou mesmo devido "pouca diversidade de contextos (Q74, MEPE).

A preparação científico-pedagógica (5,2\%) também parece ser motivo de inquietação, no sentido em que consideram necessário "Dar mais ferramentas de didática e de estratégias que possam ser utilizadas em todo o tipo de situações, nomeadamente, indisciplina e gestão de conflitos" (Q25, MPHGP); e em que "É pouca teoria para aquilo que nos é pedido: recolha e tratamento de dados, avaliação dos alunos quando é realizada a intervenção e diagnóstico correto dos alunos na fase de observação" (Q30, MMCN).

Em outros (8,3\%), é possível identificar aspectos relacionados com o processo investigativo exigido pelo decreto: "a obrigatoriedade da realização de uma investigação em contexto, uma vez que a duração da PES é demasiado reduzida para todas as exigências que a ela estão associadas" (Q111, MEPE), bem como uma "desarticulação [existente] entre as disciplinas teóricas e a prática" (Q60, MEPE).

Em síntese, pode afirmar-se que há uma referência simultânea nos pontos fortes e fracos de três dimensões: organização e duração da PES; contextos de estágio e processo de supervisão, que dizem diretamente respeito ao funcionamento da PES.

Uma outra sobreposição referente aos processos investigativos, exigidos no decretolei, como referimos anteriormente, vem evidenciar o alto consenso no discurso e a baixa intensidade da sua concretização na PES. É, aliás, o elemento mais controverso e que provoca discussão, assim como a promoção de diversos encontros científicos nacionais, nos últimos anos, por parte de instituições de ensino superior que fazem a formação.

Tal como defendem Mouraz, Leite e Fernandes (2012, p. 193), “embora a formação de professores corresponda agora ao nível de mestrado, não se pode concluir que o tempo dedicado à formação pedagógico-didática e de contato com as situações profissionais tenha aumentado", confırmando-se nesta dimensão um grau de cristalização relativamente à organização e duração da PES. 


\section{(vi) Propostas de alteração da PES no plano de estudos}

A dimensão propostas de alteração da PES no plano de estudos atual contempla as seguintes dimensões (Tabela 5): organização da PES (19,4\%); não simultaneidade da PES com outras UC (18,8\%); aumentar o período da PES (16,7\%); formas de avaliação $(14,6 \%)$; processo de supervisão $(11,1)$; outros $(6,3 \%)$; não alterar $(4,9 \%)$; locais de estágio e supervisores $(4,2 \%)$ e NS/NR (4,2\%).

Tabela 5 - Distribuição das propostas de alteração da PES no plano de estudos

\begin{tabular}{lll}
\hline & \multicolumn{2}{c}{ Propostas de alteração da PES } \\
\cline { 2 - 3 } & $\mathrm{n}$ & $\%$ \\
\hline Organização da PES & 28 & 19,4 \\
\hline Não simultaneidade da PES com outras UC & 27 & 18,8 \\
\hline Aumentar o período da PES & 24 & 16,7 \\
\hline Formas de avaliação & 21 & 14,6 \\
\hline Processo supervisivo & 16 & 11,1 \\
\hline Outros & 9 & 6,3 \\
\hline Não alterar & 7 & 4,9 \\
\hline Locais de estágio e supervisores & 6 & 4,2 \\
\hline NS/NR & 6 & 4,2 \\
\hline
\end{tabular}

Fonte: elaboração própria, com base nos dados recolhidos.

Para a organização da PES (19,4\%), há estudantes que "Tentaria[m] colocar uma oportunidade de realizar a PES mais cedo, num espaço-tempo mais reduzido" (Q5, MEPE); "o tempo de estágio e colocaria uma semana sem estágio entre as semanas de observação e as semanas de intervenção" (Q28, MPHGP); "Separaria a UC PESII, em duas UC. PESII: $2^{\circ}$ CEB, PESIII: $1^{\circ}$ CEB e Tese” (Q40, MMCN).

A não simultaneidade da PES com outras UC (18,8\%) está associada ao "facto de ter[em] de frequentar aulas ao mesmo tempo que [realizam] o estágio" (Q8, MEPE), e, por essa razão, os estudantes "alteraria[m] o facto de existirem aulas e PES ao mesmo tempo" (Q10, MEPE).

A sugestão de aumentar o período da PES (16,7\%) diz respeito "ao período de observação como ao de intervenção." (Q22, MMCN); “A carga horária, considero que este tipo de UC deveria ocupar um espaço mais proeminente na carga horária.” (Q65, MEPE).

As formas de avaliação (14,6\%) seriam alteradas considerando "o número de elementos de avaliação [...] [havendo] uma maior ponderação na avaliação dos estagiários por parte do professor cooperante (uma vez que este está presente em todas as aulas, pode, melhor do que um professor que assiste a uma aula esporádica, avaliar o desempenho progressivo dos estagiários); alteraria o sistema de atribuição de professores tutores" (Q34, MMCN). 
0 processo de supervisão (11,1\%) é mencionado sobretudo no acompanhamento por parte dos supervisores, passando a "aumenta[r] o número de observações a que devem ser sujeitas pelos professores supervisores” $\left(\mathrm{Q} 99, \mathrm{PE} 1^{\circ} \mathrm{CEB}, \mathrm{Q} 101, \mathrm{PE} 1^{\circ} \mathrm{CEB}\right)$ e no seu comportamento, pois ao que parece "há orientadores que têm de [...] estar mais tempo no estágio" (Q72, MEPE). Neste âmbito, é ainda sugerido "uma reunião intermédia entre Supervisor, Tutor e Estagiário(a) para balanço conjunto", assim como um feedback mais crítico dos trabalhos realizados semanalmente ou "então que se peçam menos documentos para que todos possam trabalhar no que é pedido mais dedicadamente e melhor" (Q60, MEPE).

Em outros (6,3\%), os(as) estudantes sugerem que "deveria ser a Coordenação de Curso a escolher os professores em função do agrupamento de escolas; isto porque a sensação que dá é que é selecionado o agrupamento $\mathrm{X}$ e só depois o agrupamento escolhe os professores A e B que poderão não corresponder aos requisitos do agrupamento" (Q22, MPHGP); "Mais UC relacionadas com o ensino prático e muito menos teoria” (Q76, $\left.\mathrm{PE} 1^{\circ} \mathrm{CEB}\right)$; “Ajudas ao nível do transporte e alimentação para os estudantes” (Q26, MEPE).

Há estudantes que preferem não alterar (4,9\%) o plano de estudos.

Em locais de estágio e supervisores (4,2\%), os estudantes sugerem “[a seleção de] professores tutores competentes, não só a nível dos conhecimentos como também ao nível da relação com os alunos" (Q21, PE1 $\left.{ }^{\circ} \mathrm{CEB}\right)$.

Por fim, há estudantes que ainda não se sentem preparados para este balanço - NS/ NR (4,2\%): "Ainda não sei responder com certeza." (Q82, MMCN); "Neste momento ainda não consigo fazer este balanço." (Q9, MEPE).

Em síntese, ao atentarmos nas dimensões pontos fracos e propostas de alteração da PES no plano de estudos atual, é possível verificar que as sugestões de alterações feitas pelos(as) estudantes vão muito ao encontro do que são as fragilidades enumeradas na PES. Destacam-se a necessidade de organização da PES, assim como a sua duração e a ocorrência, em simultâneo, da PES com outras unidades curriculares do curso.

Estes dados remetem para a necessidade de debater a dimensão da temporalidade, essencial na construção da profissionalidade. Talvez à semelhança de um grande movimento que surgiu no início do século XXI - Slow Movement - que reivindica uma desaceleração do tempo e do ritmo em várias dimensões da vida social (Slow Food, Slow Cities, Slow Tourism, Slow Sex, Slow Money, Slow Books, Slow Schools, Slow Education, Slow Living, Slow Science, entre outros), estaremos a precisar de uma Slow Professional Practice.

É efetivamente preciso tempo para aceitar as mudanças, para pensar, para escrever, para (re)construir práticas, para construir a profissão, e este tempo necessário para construir a profissão parece não ter espaço no tempo de Bolonha.

\section{Considerações finais}

As seis dimensões analisadas permitem-nos identificar dois processos de forças contrárias, tal como afirmados em trabalhos semelhantes a este, as narrativas e os discursos sobre a PES estão em tensão, ou mesmo em contradição, com a ação (BIEN; SELLAND, 2018). Contrariamente ao preconizado, parece perceber-se a ausência de uma prática em 
diálogo permanente com a teoria, no sentido em que são os(as) próprios(as) estudantes que, reconhecendo a sua importância, se mostram igualmente conscientes do seu pouco aprofundamento na construção da profissão durante a PES.

Verifica-se, por um lado, a cristalização dos referenciais teóricos mobilizados pelos(as) estudantes nas suas reflexões sobre a PES; a coexistência de modelos pedagógicos ou curriculares híbridos, inexistentes ou desvalorizados; e a permanência do duo psicologia e pedagogia, na sua versão clássica, sem que se mobilizem outras áreas de conhecimento. No fundo, parece existir alguma dificuldade para colocar em prática modelos inovadores.

A reflexão e a fusão dos(as) intervenientes e dos processos caracteriza-se por uma proliferação de processos e saberes espartilhados e híbridos. Ao invés do muito tempo passado na escola, com as crianças e com os pares para que se respeite o processo isomórfico inerente ao desenvolvimento profissional do(a) (futuro(a)) educador(a) ou professor(a), parece imperar a lógica de um conhecimento desagregado, que vai sendo construído nas diferentes seções sem que exista um espaço e um tempo de pôr em comum, tão necessários à construção de uma sólida identidade profissional. Veja-se esta pressa em transmitir conhecimento, quando há uma sobreposição da PES com UC teóricas que, apesar de aparentarem estar em articulação com o estágio, não há tempo para que os(as) estudantes se apercebam dessa relação e do seu contributo no processo. Do seu testemunho, é possível perceber o desconforto que a coabitação que destes dois saberes, teórico e prático, lhes provoca, não lhes permitindo sequer o seu proveito para melhorar a sua preparação científico-pedagógica.

As propostas de alteração que os(as) estudantes fazem também parecem estar em consonância com os pontos fracos por eles(as) identificados. 0 que poderá significar que há uma relativa consciência de como se pode desenvolver o processo formativo da sua profissão, faltando-lhes, no entanto, aparentemente, saber a combinação ou as fórmulas para manipular todas as ferramentas. É algo que só é possivel através da triangulação de saberes provindos de diferentes especialistas, e orquestrado pelos educadores(as) e professores(as) detentores(as) de mais experiências. É como se o fato de nunca terem saído do espaço do jardim de infância ou da escola e da sala de aula/atividade lhes permitisse aprender quase de forma implícita o que é ser educador(a) ou professor(a).

Por outro, reconhece-se a descristalização, pelo reconhecimento do lugar central que a PES ocupa na sua formação profissional e pela mobilização da fundamentação teórica que a maioria dos(as) estudantes afirma convocar quando da realização, maioritariamente, semanal das reflexões escritas.

Uma melhor e mais estreita relação entre a teoria e a prática é também uma evidência manifestada pelos(as) participantes neste estudo, quer como um desejo futuro, quer como um desejo imediato na sua própria formação inicial. Mas como poderão as escolas de formação aliar estes dois campos, se à partida parecem já tão espartilharmos, fruto de um "ímpeto normativista dos processos de formação" (RAMALHO, 2015, p. 282) que preconizam a organização dos mestrados profissionalizantes? 


\section{Referências}

ALARCÃO, Isabel; ROLDÃO, Maria do Céu. Supervisão: um contexto de desenvolvimento profissional dos professores. Mangualde: Pedagogo, 2010.

BALL, Stephen. Diretrizes políticas globais e relações políticas locais em educação. Currículo sem Fronteiras, Porto Alegre, v. 1, n. 2, p. 99-116, 2001.

BIANCHETTI, Lucídio; SGUISSARDI, Valdemar (Org.). Dilemas da pós-graduação: gestão e avaliação. Campinas: Autores Associados, 2009.

BIEN, Andrea; SELLAND, Makenzie. Living the stories we tell: the sociopolitical context of enacting teaching stories. Teaching and Teacher Education, Amsterdã, v. 69, p. 85-94, 2018.

BRIT0, Elisabete. (Re)pensar a formação de professores no contexto do Processo de Bolonha: que constrangimentos? Que Alternativas. In: CONSELHO NACIONAL DE EDUCAÇÃO (Ed.). Formação inicial de professores. Lisboa: CNE, 2015. p. 249-271.

CARDONA, Maria João. Contributos para a história do grupo dos profissionais de educação de infância em Portugal. Interacções, Santarém, n. 9, p. 4-31, 2008.

COCHRAN-SMITH, Marylin; VILLEGAS, Ana Maria. Research on teacher preparation: charting the landscape of a sprawling field. In: GITOMER, Drew; BELLS, Courtney (Ed.). Handbook of research on teaching. Washington, DC: AERA, 2016. p. 439-547.

CRESWELL, John. Research design: qualitative, quantitative \& mixed methods approaches, Washington, DC: Sage, 2014.

DEWEY, John. Experiência e educação. Petrópolis: Vozes, 2011 [1938].

ESTRELA, Maria Teresa. Profissão docente: dimensões afectivas e éticas. Porto: Areal, 2010.

ESTRELA, Maria Teresa; ESTEVES, Manuela; RODRIGUES, Ângela. Síntese da investigação sobre formação inicial de professores em Portugal (1990-2000). Porto: Porto Editora, 2002.

EUROPEAN COMMISSION/EACEA/EURYDICE. The European higher education area in 2018: Bologna process implementation report. Luxembourg: Office of the European Union, 2018.

FERREIRA, Pedro. Formação inicial de professores do $1^{\circ} \mathrm{CEB}$, supervisão pedagógica e inovação curricular: perceções e reflexões de supervisores e estagiários. 2016. 503 f. Tese (Doutoramento em Ciências da Educação) - Universidade do Porto, Porto, 2016.

FERREIRA, Pedro; FERNANDES, Preciosa. Formação inicial de professores do $1^{\circ} \mathrm{CEB}$ : uma análise focada nos relatórios de estágio. Saber \& Educar, Porto, n. 20, p. 244-254, 2 dez. 2015. 
FORMOSINHO, João (Coord.) Formação de professores: aprendizagem profissional e acção docente. Porto: Porto Editora, 2009.

FREIRE, Paulo. Pedagogia da autonomia: saberes necessários à prática educativa. Rio de Janeiro: Paz e Terra, 1996.

GALVÃO, Cecília; PONTE, João Pedro (Org.). Práticas de formação inicial de professores: participantes e dinâmicas. Lisboa: Instituto de Educação, 2018.

LEITE, Carlinda. Percursos e tendências recentes da formação de professores em Portugal. Educação, Porto Alegre, v. 3, n. 57, p. 371-389, set./dez. 2005.

LIMA, Licínio; AZEVEDO, Mário; CATANI, Afrânio. 0 Processo de Bolonha, a avaliação da educação superior e algumas considerações sobre a universidade nova, Avaliação, Campinas, v. 13, n. 1, p. 7-36, mar. 2008.

MOURAZ, Ana; LEIE, Carlinda; FERNANDES, Preciosa. A formação inicial de professores em Portugal decorrente do Processo de Bolonha: uma análise a partir do "olhar" de professores e de estudantes. Revista Portuguesa de Pedagogia, Coimbra, v. 2, n. 42, p. 189-209, jan. 2012.

NÓVOA, António. Professionnalisation des enseignants et sciences de l'éducation": paedagogica historica. International Journal of the History of Education, Birmingham, III (supplementary series), p. 403-430, 1998.

NÓVOA, António. Professores: imagens do futuro presente. Lisboa: Educa, 2009.

PORTUGAL. Assembleia da República. Decreto-lei n. ${ }^{\circ}$ 74/2006, de 24 de março. Aprova o regime jurídico dos graus e diplomas do ensino superior. Lisboa: AR, 2006. Disponível em: <https://www.fct.pt/apoios/ bolsas/DL_74_2006.pdf>. Acesso em: 28 jan. 2018.

PORTUGAL. Assembleia da República. Lei 46/86, de 14 de outubro. Segunda alteração à Lei de Bases do Sistema Educativo e primeira alteração à Lei de Bases do Financiamento do Ensino Superior. Lisboa: AR, 1986. Disponível em: <https://tinyurl.com/y8vllh6f>. Acesso em: 28 jan. 2018.

PORTUGAL. Assembleia da República. Lei 49/2005, de 30 de agosto. Segunda alteração à Lei de Bases do Sistema Educativo e primeira alteração à Lei de Bases do Financiamento do Ensino Superior. Lisboa: AR, 2005. Disponível em: <https://dre.pt/web/guest/pesquisa/-/search/245336/details/maximized>. Acesso em: 28 jan. 2018.

PORTUGAL. Assembleia da República. Lei 115/97, de 19 de setembro. Alteração à Lei n. ${ }^{\circ}$ 46/86, de 14 de Outubro (Lei de Bases do Sistema Educativo). Lisboa: AR, 1997. Disponível em: <https://dre.pt/pesquisa/-/ search/653145/details/maximized>. Acesso em: 28 jan. 2018.

PORTUGAL. Ministério da Educação. Decreto-lei n. ${ }^{\circ}$ 43/2007, de 22 de fevereiro. Aprova o regime jurídico da habilitação profissional para a docência na educação pré-escolar e nos ensinos básico e secundário. Lisboa: ME, 2007. Disponível em: <https://dre.pt/pesquisa/-/search/517819/details/maximized>. Acesso em: 28 jan. 2018. 
PORTUGAL. Ministério da Educação. Decreto-lei n. ${ }^{0}$ 79/2014, de 22 de maio. Aprova o regime jurídico da habilitação profissional para a docência na educação pré-escolar e nos ensinos básico e secundário. Lisboa: ME, 2014. Disponível em: <https://dre.pt/pesquisa/-/search/25344769/details/maximized>. Acesso em: 28 jan. 2018.

PORTUGAL. Ministério da Educação. Decreto-lei 240/2001, de 30 de agosto. Define-se 0 perfil de desempenho comum aos educadores de infância e aos professores dos ensinos básico e secundário. Lisboa: ME, 2001. Disponível em: <https://tinyurl.com/y7zz3em5>. Acesso em: 28 jan. 2018.

PORTUGAL. Ministério das Finanças e da Educação. Portaria 336/88, de 28 de Maio. Regulamenta a prática pedagógica dos cursos de formação inicial de educadores de infância e de professores dos $1^{\circ}$ e $2^{\circ}$ ciclos do ensino básico. Lisboa: MF: ME, 1988. Disponível em: <http://publicos.pt/documento/id374231/ portaria-336/88>. Acesso em: 28 jan. 2018.

RAMALHO, Henrique. Pedagógica e didática dos professores: entre a cultura da performatividade de feição técnico implementalista e o desafio da formação investigativo reflexiva. Saber \& Educar, Porto, n. 20, p. 254263,2015

ROLDÃO, Maria do Céu. A formação de professores como objecto de pesquisa: contributos para a construção do campo de estudo a partir de pesquisas portuguesas. Revista Eletrônica de Educação, São Carlos, v. 1, n. 1, p. 50-118, jan./jun. 2007.

ROLDÃO, Maria do Céu. Formar professores: os desafios da profissionalidade e o currículo. Aveiro: Universidade de Aveiro, 2000.

SERRALHEIRO, José. 0 Processo de Bolonha e a formação dos educadores e professores portugueses. Porto: Profedições, 2005.

SILVA, Isabel. Oficina de formação: gerir o currículo na educação pré-escolar: planeamento e avaliação na perspetiva das OCEPE 2016. Lisboa: Direção Geral de Educação, 2017.

TOMÁS, Catarina; GONÇALVES, Carolina. A prática de ensino supervisionada nos mestrados de formação de educadores/as e professores/as em Portugal: vozes das coordenadoras. Práxis Educacional, Vitória da Conquista, v. 14, n. 30, p. 111-134, out./dez. 2018. https://doi.org/10.22481/praxis.v14i30.4363

VILARINHO, Maria Emília. Políticas educativas para a infância: o caso da educação pré-wscolar em Portugal (1995-2010). In: DORNELLES, Leni; FERNANDES, Natália (Org.). Perspetivas sociológicas e educacionais em estudos da criança: as marcas das dialogicidades luso-brasileiras. Braga: CIEC/UM, 2012. p. 365-384.

Recebido em: 15.08 .2018

Revisado em: 06.11.2018

Aprovado em: 27.11.2018 
Carolina Gonçalves é doutorada em ciências da educação - teoria curricular e metodologias de ensino. É professora adjunta no Departamento de Formação e Investigação em Currículo e Didáticas, na Escola Superior de Educação de Lisboa e investigadora no Centro Interdisciplinar de Ciências Sociais (CICS.NOVA), Faculdade de Ciências Sociais e Humanas (FCSH/NOVA).

Catarina Tomás é doutorada em estudos da criança. É professora adjunta no Departamento de Formação e Investigação em Educação e Desenvolvimento, na Escola Superior de Educação de Lisboa e investigadora no Centro Interdisciplinar de Ciências Sociais (CICS.NOVA), Faculdade de Ciências Sociais e Humanas (FCSH/NOVA). 